\title{
ASSESMEN TINGKAT PARTISIPASI PETERNAK DALAM KEGIATAN INSEMINASI BUATAN DI KECAMATAN SELEBAR KOTA BENGKULU
}

\section{ASSESSMENT OF FARMER'S PARTICIPATION RATE ON ARTIFICIAL INSEMINATION PROGRAM IN DISTRICT OF SELEBAR BENGKULU CITY}

\author{
Yossie Yumiati ${ }^{1)}$ Heri Dwi Putranto ${ }^{2)}$ Eva Ramalia Sari ${ }^{3)}$ \\ ${ }^{1)}$ Program Studi Agribisnis Fakultas Pertanian Universitas Dehasen Bengkulu \\ 2) Jurusan Peternakan Fakultas Pertanian Universitas Bengkulu \\ ${ }^{3)}$ Program Studi Teknologi Pertanian Fakultas Pertanian Universitas Dehasen \\ Email : yosiyusni1711@yahoo.com
}

\begin{abstract}
ABSTRAK
Tingkat kesuksesan penerapan program Inseminasi Buatan (IB) yang masih belum maksimal dikarenakan masih adanya sikap petani/ peternak yang belum mengetahui program IB secara menyeluruh dan belum bisa menerima program tersebut. Selain itu besaran assesmen dari tingkat partisipasi peternak dapat dilihat dari tingkat partisipasi dalam perencanaan, tingkat partisipasi dalam pelaksanaan dan tingkat partisipasi dalam pemanfaatan hasil. Tujuan penelitian ini adalah untuk mengetahui besaran assesmen tingkat partisipasi peternak dalam kegiatan Inseminasi Buatan. Penelitian telah dilaksanakan pada bulan MeiJuli 2016 di Kecamatan Selebar Kota Bengkulu. Adapun responden terpilih secara acak (simpel random sampling) sebanyak 77 orang. Data yang diperoleh baik data primer atau sekunder dianlisa secara kualitatif dan kuantitatif. Metode analisa data yang digunakan untuk melihat besarnya assesmen tingkat partisipasi antara variabel dependen (Y) dan independen $(\mathrm{X})$ dilakukan analisis regresi berganda dengan program statistik computer costat versi 9.00 .

Berdasarkan hasil pengamatan dan hasil analisis regresi yang dilakukan maka dapat diperoleh hasil bahwa besaran assesmen tingkat pertisipasi yang mempengaruhi secara nyata dalam mengikuti pelaksanaan kegiatan inseminasi buatan adalah umur peternak dan jumlah ternak potong yang dimiliki responden. Berdasarkan hasil perhitungan koefisen determinasi $\left(\mathrm{r}^{2}\right)$ hanya memberikan sumbangan sebesar 0,1958 dari variabel independen terhadap variabel dependen. Sedangkan berdasarkan hasil perhitungan koefisen korelasi (r), variabel independen dari karakteristik responden terhadap variabel dependen tingkat partisipasi ini mempunyai hubungan yang lemah sampai dengan sedang, karena hanya sebesar 0,4425 masih jauh dari 1.
\end{abstract}

Kata Kunci: Assesmen tingkat partisipasi, peternak sapi potong, kegiatan IB

\section{ABSTRACT}

The successfulness of artificial insemination program in Bengkulu still low caused by farmer's less knowledge and their lack of receptiveness about the program itself. The purpose of the study was to assess farmer's participation rate on artificial insemination program in Bengkulu city.The study.conducted during May to June in Selebar District, bengkulu City. By simple random method, there were 77 farmers were interviewed by using a written quistionaire. Collacted data was analyzed by comparing the dependent factors $(Y)$ and independent factor $(X)$ thus continued by applying a multiple regression method. 
The results showed of observations and regression analysis results conducted then it can be obtained that the amount of assessment of the level of participation that significantly influence in following the implementation of artificial insemination activities is the age of farmers and the number of cattle owned respondents. Result on the calculation of coefficient of determination $(r 2)$ only give contribution of 0.1958 from independent variable to dependent variable. While based on the calculation of correlation coefficient ( $r)$, independent variables of the characteristics of respondents to the dependent variable of this participation rate have a weak to medium relations, because only 0.4425 is still far from 1.

Keywords : Assessment of participation rate, the cattle farmer's, AI program

\section{PENDAHULUAN}

\section{Latar Belakang}

Tingkat keberhasilan penyebaran teknologi IB dapat bersumber dari kelemahan sistem pelayanan, kelemahan sumberdaya manusia terutama petugas IB (inseminator), kelemahan sumberdaya manusia (peternak) serta kesulitan jangkauan wilayah yang jauh. Apabila dilihat dari sudut pandang Sosial Ekonomi Pertanian, adanya unsur penerimaan teknologi yang cukup lambat bisa diterima oleh peternak dapat menjadi salah satu kelemahan utama dalam penerapan program IB.

Menurut Mardikanto (2009), adanya partisipasi peternak dalam penyuluhan merupakan salah satu bentuk dari adopsi teknologi. Semakin tinggi tingkat partisipasi menyebabkan pelaksanaan penyuluhan akan lebih berorientasi kepada kebutuhan petani. Lebih jauh, materi penyuluhan yang akan memperhatikan keberagaman lokal dan sumberdaya yang dimiliki serta metode penyebarluasan inovasi yang efektif dan efisien.

Dalam program IB di Kota Bengkulu, penyuluh memiliki peranan yang sangat penting. Interaksi yang komunikatif antara peternak dan penyuluh (inseminator) sudah terjalin dan terbangun rasa saling percaya. Hal ini diperkuat oleh Padmaningrum (2014) yang menyatakan bahwa penyuluh memegang peranan penting dalam pengembangan dan diseminasi inovasi peternakan. Menurut Valera et al. (1987), diseminasi teknologi, informasi barang dan layanan yang dilakukan oleh seorang penyuluh atau teknisi kepada petani/peternak akan dapat meningkatkan kualitas hidup masyarakat di pedesaan.

Dengan melihat keterlibatan dan interaksi antara petani/peternak dan inseminator, maka penulis tertarik untuk mengetahui besarnya assesmen tingkat partisispasi peternak dalam kegiatan Inseminasi Buatan di Kecamatan Selebar Kota Bengkulu. 
METODE PENELITIAN

Penelitian telah dilaksanakan di Kecamatan Selebar Kota Bengkulu Provinsi Bengkulu dimana penentuan lokasi dilakukan dengan cara purposive sampling di Kota Bengkulu dengan pertimbangan berdasarkan data jumlah populasi ternak sapi potong tertinggi. Kecamatan Selebar memiliki populasi sebesar 1.581 ekor dan merupakan populasi tertinggi di Kota Bengkulu (Anonimous, 2014). Metode penentuan sampel ditentukan secara acak (simpel random sampling) terpilih sebanyak 77 orang responden.

Data penelitian berupa data primer dan sekunder yang bersifat kualitatif dipaparkan secara deskriptif (Yumiati, 2012). Selanjutnya data yang bersifat kuantitatif dianalisis secara statistik. Untuk menganalisis hubungan antara variabel dependen $(\mathrm{Y})$ dan independen (X) dilakukan analisis regresi berganda dengan program statistik computer costat versi 9.00, dengan model menurut Mittlboeck and Schemper (1996) :

$\mathbf{Y}=\beta_{0}+\beta_{1} X_{1}+\beta_{2} X_{2}+\beta_{3} X_{3}+\beta_{4} X_{4}+\ldots \beta_{6} X_{6}$

Keterangan :

$\mathrm{Y}=$ Tingkat Partisipasi

$\beta_{0} \ldots \beta_{6}=$ Koefisien regresi

$\mathrm{X} 1=$ Umur (th)

$\mathrm{X} 2=$ Pendidikan formal (th)

$\mathrm{X} 3=$ Pengalaman beternak sapi potong

(th)
$\mathrm{X} 4=$ Jumlah ternak potong (ekor)

$\mathrm{X} 5=$ Jumlah tanggungan keluarga (orang)

$\mathrm{X} 6=$ Pendapatan Keluarga $(\mathrm{Rp})$

Untuk menganalisis kekuatan hubungan antara variabel dependent (Y) dengan independent $(\mathrm{X})$ dilakukan analisis korelasi Rank Spearman dengan menggunakan program Costat versi 9.00.

\section{HASIL DAN PEMBAHASAN}

\section{Assesmen Tingkat Partisipasi peternak}

1. Partisipasi dalam sosialisasi adalah keikutsertaan peternak terhadap segala kegiatan yang di adakan pemerintah terkait masalah peternakan sapi potong

2. Partisipasi dalam penyuluhan adalah keikutsertaan peternak terhadap keinginan mendapatkan ilmu dari materi - materi yang disampaikan.

3. Partisipasi dalam pelatihan adalah keikutsertaan peternak dalam menerapkan ilmu-ilmu baru yang didapat dalam penyuluhan.

4. Partisipasi dalam Implementasi 1 tahun terakhir, 2 tahun terakhir dan 3 tahun terakhir adalah keaktifan peternak dalam mengikuti program IB yang telah berjalan dari tiap-tiap tahun

Partisipasi disini mempunyai arti keterlibatan masyarakat lokal dalam setiap fase kegiatan mulai dari perencanaan dan 
pengambilan keputusan, implementasi, evaluasi dan pemanfaatan (Awang, 1999).

Dalam penelitian ini pengambilan hipotesis dilakukan dengan melihat nilai probabilitasnya $(P)$. Menurut Gujarati (2003), jika nilai $(P)$ lebih kecil dari nilai alpha $(\alpha)$ maka dengan tingkat keyakinan (1- $\alpha$ ) hipotesis ditolak. Hasil perhitungan dengan menggunakan program costat pada analisis multiple regression dapat dilihat pada (Tabel 1).

Berdasarkan hasil perhitungan diperoleh persaman regresi : $\mathrm{Y}=0,3530+$ $0,0316 \mathrm{X} 1+0,0405 \mathrm{X} 2+0,0039 \mathrm{X} 3+$ $0,1069 X 4+0,0775 X 5+-0,2335 X 6$ dengan koefisen korelasi (r) 0,4425 dan koefisen determinasi $\left(r^{2}\right)$ 0,1958. Hasil anova untuk regresi (Tabel 1) ada hubungan linier antara variable dependent $\mathrm{Y}$ dengan independent $\mathrm{X}(\mathrm{P}<0,05)$. Variable independen yang berpengaruh nyata terhadap tingkat partisipasi dalam pelaksanaan program IB adalah umur peternak $(\mathrm{X} 1)$ dengan $(\mathrm{P}<0,01)$ dan jumlah ternak yang dimiliki (X4) dengan $(\mathrm{P}<0,05)$ sedangkan variable independent yang tidak berpengaruh nyata adalah tingkat pendidikan formal (X2), pengalaman beternak sapi (X3), jumlah tangungan keluarga (X5), pendapatan keluarga (X6).

Tabel 1. Multiple Regression

\begin{tabular}{cccccc}
\hline Sumber & JK & DB & KT & F & P \\
\hline Total & 76,8571 & 76 & & & \\
Regression & 15,0523 & 6 & 2,5087 & 2,8414 & $0,0156 *$ \\
X1 & 8,5562 & 1 & 8,5562 & 9,6907 & $0,0027 * *$ \\
X2 & 0,1690 & 1 & 0,1690 & 0,1914 & $0,6631 \mathrm{~ns}$ \\
X3 & 1,1954 & 1 & 1,1954 & 1,3540 & $0,2485 \mathrm{~ns}$ \\
X4 & 4,3066 & 1 & 4,3066 & 4,8776 & $0,0305 *$ \\
X5 & 0,0839 & 1 & 0,0839 & 0,0950 & $0,7589 \mathrm{~ns}$ \\
X6 & 0,7413 & 1 & 0,7413 & 0,8395 & $0,3627 \mathrm{~ns}$ \\
Error & 61,8049 & 70 & 0,8829 & &
\end{tabular}

Keterangan nyata

(*) Berpengaruh nyata, $(* *)$ Sangat berpengaruh nyata, (ns) Tidak berpengaruh

Sumber : Data primer (2016) 
Berdasarkan Tabel 1. dapat diketahui bahwa hasil total keseluruhan dari analisis koefisen regression sebesar 0,0269 dengan nilai $\mathrm{P}$ sebesar 0,0156 yang lebih kecil dari pada $\alpha 0,05$, yang berarti mempunyai pengaruh nyata, maka dapat disimpulkan bahwa model regresi logistik secara keseluruhan dapat menjelaskan atau memprediksi peternak dalam mengikuti pelaksanaan program IB di Kecamatan Selebar Kota Bengkulu. Berdasarkan analisi regresi variabel yang mempunyai pengaruh adalah umur peternak (X1) dengan nilai P 0,0027 dan jumlah kepemilikan ternak (X2) dengan nilai P 0,0305 .

Berdasarkan analisis diperoleh nilai r (korelasi) adalah sebesar 0.4425 , maka dapat dikatakan bahwa hubungan antara variabel independen $\mathrm{X} 1, \mathrm{X} 2, \mathrm{X} 3, \mathrm{X} 4, \mathrm{X} 5, \mathrm{X} 6$ (umur peternak, tingkat pendidikan, pengalaman beternak, jumlah ternak, jumlah tanggungan keluarga, pendapatan keluarga) dengan variabel dependen Y (tingkat paritisipasi) mempunyai hubungan yang lemah sampai dengan sedang karena nilai $r$ sebesar 0,4425 masih belum mendekati nilai 1 . Sedangkan berdasarkan nilai $\mathrm{r}^{2}$ (koefisen determinasi) sebesar 0.1958 atau $19,58 \%$ hal ini menggambarkan bahwa sumbangan variabel independen $\mathrm{X} 1, \mathrm{X} 2, \mathrm{X} 3, \mathrm{X} 4, \mathrm{X} 5, \mathrm{X} 6$ terhadap besar kecilnya variabel dependen Y sebesar 19,58\% sedangkan sisanya merupakan sumbangan dari variabel lain yang tidak termasuk dalam model.

Untuk melihat pengaruh masingmasing variabel bebas yang diteliti digunakan nilai $\mathrm{P}$ masing-masing variabel dibandingkan dengan nilai alpha $(\alpha)$ sebesar 0,05. Pengaruh masing-masing variabel penelitian terhadap keputusan peternak dijelaskan secara rinci sebagai berikut:

\section{Umur Peternak}

Umur peternak memiliki koefisen regresi sebesar 0,0316, dimana nilai $\mathrm{P}$ sebesar 0,0027 lebih kecil dari pada $\alpha 0,05$ yaitu sangat berpengaruh nyata. Artinya umur peternak mempengaruhi tingkat partisipasi peternak dalam mengikuti pelaksanaan program IB di Kecamatan Selebar Kota Bengkulu, karena berdasarkan hasil penelitian (Tabel 2) diketahui bahwa persentase tertinggi $61,03 \%$ untuk umur responden yang ikut dalam program inseminasi buatan berada pada kisaran umur 44 - 53 tahun 47 responden.

Tabel 2. Umur Responden

\begin{tabular}{lccc}
\hline No & Umur & Jumlah Responden & Persentase \\
& $($ Tahun $)$ & $($ orang) & $(\%)$ \\
\hline
\end{tabular}




\begin{tabular}{cccc}
1 & $24-33$ & 7 & 9,0909 \\
2 & $34-43$ & 19 & 24,6753 \\
3 & $44-53$ & 47 & 61,0390 \\
4 & $>54$ & 4 & 5,1948 \\
\hline Total & & $\mathbf{7 7}$ & $\mathbf{1 0 0}$ \\
\hline
\end{tabular}

Sumber : Data Primer (2016)

Hal ini sejalan menurut Soekartawi (1996), umur produktif untuk orang Indonesia berada pada kisaran 15 64 tahun. Menurut Saragih (2000) bahwa usia mempunyai pengaruh terhadap produktifitas kerja pada jenis pekerjaan yang mengandalkan tenaga fisik. Kemampuan seseorang dalam bekerja sangat dipengaruhi oleh umur dari orang tersebut. Seseorang akan lebih mampu dalam bekerja optimal apabila berada pada usia produktif. Untuk parameter umur seseorang dalam menerima atau mengadopsi inovasi baru, umur $25-40$ tahun biasanya bersifat pengetrap dini, umur 41 - 45 pengetrap awal, umur 46 50 tahun pengetrap akhir dan lebih dari 50 tahun dapat menjadi golongan penolak (Nurlina, 2007).

\section{Pendidikan Formal}

Pendidikan yang ditempuh peternak pada penelitian ini memiliki koefisen regresi sebesar 0,0405 dengan nilai $\mathrm{P}$ sebesar 0,6631 yang lebih besar dari pada $\alpha 0,05$ yaitu tidak berpengaruh nyata. Artinya pendidikan tidak mempengaruhi tingkat partisipasi peternak untuk mengikuti pelaksanaan program IB, hal ini dikarenakan dari rendahnya tingkat pendidikan responden. Berdasarkan hasil penelitian (Tabel 3) terlihat bahwa persentase terbesar tingkat pendidikan formal peternak yang ikut program IB pada katagori 9 tahun atau SMP sebesar $50.64 \%$, kemudian di ikuti oleh SD $24.67 \%$, SMA $23.37 \%$ dan sarjana $1.29 \%$. Tingkat pendidikan yang tinggi akan mempermudah seseorang untuk berfikir secara rasional dan lebih terbuka dalam menerima hal - hal baru. Rendahnya tingkat pendidikan akan berpeluang pada rendahnya adopsi teknologi. Melalui pendidikan peternak mempunyai pengetahuan, keterampilan dan cara baru dalam melakukan kegiatan usaha sehingga dengan pendidikan yang lebih tinggi hasil juga lebih baik (Mosher, 1987).

Rendahnya tingkat pendidikan akan berpeluang pada rendahnya adopsi teknologi (Program IB). Menurut Mosher 
(1987) Melalui pendidikan peternak mempunyai pengetahuan, keterampilan dan cara baru dalam melakukan kegiatan usaha sehingga dengan pendidikan yang lebih tinggi hasil juga lebih baik.

\section{Pengalaman Beternak Sapi Potong}

Pengalaman Beternak Sapi potong memiliki koefisen regresi sebesar 0,0039 dengan nilai $\mathrm{P}$ sebesar 0,2485 yang lebih besar dari $\alpha 0,05$ yaitu tidak berpengaruh nyata. Dengan demikian artinya pengalaman beternak sapi potong tidak mempengaruhi tingkat partisipasi peternak untuk mengikuti pelaksanaan dalam program IB, hal ini menunjukan bahwa pengalaman peternak dalam usaha ternak sapi potong ini masih belum cukup lama sehingga keinginan untuk berpartisipasi dalam pelaksanaan program IB ini masih relative rendah. Dapat dilihat pada (Tabel 4) pengalaman responden beternak sapi potong 13-22 tahun adalah 35,06\%, 3-12 tahun adalah $31,17 \%, 23-32$ tahun $29,87 \%,>33$ tahun $3,90 \%$.

$$
\text { Menurut Walker }
$$

Pengalaman adalah hasil akumulasi dari proses mengalaminya seseorang, yang selanjutnya mempengaruhi terhadap respon yang diterimanya guna memutuskan sesuatu yang baru baginya.

\section{Jumlah Kepemilikan Ternak}

Jumlah ternak yang dimiliki responden mempunyai koefisen regresi sebesar 0,1069 dengan nilai $\mathrm{P}$ 0,0305 yang lebih kecil dari $\alpha \quad 0,05$ yaitu berpengaruh nyata. Artinya jumlah ternak yang dimiliki responden berpengaruh terhadap tingkat partisipasi peternak dalam mengikuti pelaksanaan program IB. Dengan kata lain semakin besar jumlah ternak yang dimiliki akan menjadi pertimbangan besar peternak untuk berpartisipasi dalam mengikuti pelaksanaan program IB, karena diidentifikasi lebih kearah efisensi dan keuntungan lebih yaitu mendapatkan bibit sapi unggul. Setelah dikelompokkan menurut (Tabel 5) responden yang 5-7 ekor ternak 36 responden (46,75\%), 2-4 ekor ternak 20 responden $(25,97 \%), 8-10$ ekor ternak 14 responden $(18,18 \%),>11$ ekor ternak 7 responden $(9,09 \%)$. 
Tabel 3. Tingkat Pendidikan Formal Responden

\begin{tabular}{cccc}
\hline No & $\begin{array}{c}\text { Pendidikan } \\
\text { (Tahun) }\end{array}$ & $\begin{array}{c}\text { Jumlah Peternak } \\
(\text { Orang) }\end{array}$ & $\begin{array}{c}\text { Persentase } \\
(\boldsymbol{\%})\end{array}$ \\
\hline 1 & SD $(1-6)$ & 19 & 24,6753 \\
2 & SMP $(7-9)$ & 39 & 50,6494 \\
3 & SMA $(10-12)$ & 18 & 23,3766 \\
4 & SARJANA $(13-16)$ & 1 & 1,2987 \\
\hline Total & & $\mathbf{7 7}$ & $\mathbf{1 0 0}$
\end{tabular}

Sumber : Data Primer (2016)

Tabel 4 . Pengalaman Responden Beternak Sapi Potong

\begin{tabular}{cccc}
\hline No & $\begin{array}{c}\text { Pengalaman Beternak Sapi Potong } \\
\text { ( Tahun ) }\end{array}$ & $\begin{array}{c}\text { Jumlah Responden } \\
\text { (orang) }\end{array}$ & $\begin{array}{c}\text { Persentase } \\
(\boldsymbol{\%})\end{array}$ \\
\hline 1 & $3-12$ Tahun & 24 & 31,1688 \\
2 & $13-22$ tahun & 27 & 35,0649 \\
3 & $23-32$ tahun & 23 & 29,8701 \\
4 & $>33$ Tahun & 3 & 3,8961 \\
\hline Total & & $\mathbf{7 7}$ & $\mathbf{1 0 0}$ \\
\hline
\end{tabular}

Sumber : Data Primer (2016)

Tabel 5. Jumlah Kepemilikan Ternak Sapi Potong

\begin{tabular}{cccc}
\hline No & $\begin{array}{c}\text { Jumlah Ternak } \\
\text { (Ekor) }\end{array}$ & $\begin{array}{c}\text { Jumlah Responden } \\
\text { (Orang) }\end{array}$ & $\begin{array}{c}\text { Persentase } \\
(\boldsymbol{\%})\end{array}$ \\
\hline 1 & $2-4$ ekor & 20 & 25,9740 \\
2 & $5-7$ ekor & 36 & 46,7532 \\
3 & $8-10$ ekor & 14 & 18,1818 \\
4 & $>11$ ekor & 7 & 9,0909 \\
\hline Total & & $\mathbf{7 7}$ & $\mathbf{1 0 0}$ \\
\hline
\end{tabular}

Sumber : Data Primer (2014) 
Hal ini sejalan Menurut Rogers (1995) proses pengambilan keputusan seseorang (peternak) apakah menerima atau menolak suatu inovasi (Program IB) tergantung pada sikap mental, situasi intern (karakteristik Responden) dan situasi ekstern (karakteristik usaha) meliputi tingkat kepemilikan ternak sapi dan pendapatan rumah tangga (Hornik, 1988).

\section{Jumlah Tanggungan Keluarga}

Jumlah tanggungan keluarga memiliki koefisen regresi sebesar 0,0775 dengan nilai $\mathrm{P}$ sebesar 0.7589 yang lebih besar dari a 0,05 yaitu tidak berpengaruh nyata. Dengan demikian artinya jumlah tanggungan keluarga tidak berpengaruh terhadap tingkat partisipasi peternak untuk mengikuti pelaksanaan program IB. Dengan kata lain peternak kurang berminat berpartisipasi dalam program IB. Apabila jumlah tanggungan keluarganya banyak maka kebutuhan keluarga semakin tinggi. Oleh karena itu dengan mengikuti program IB, masih kurang untuk meningkatkan pendapatan usaha peternakan sapi potong untuk mencukupi kebutuhan keluarga. Dibutuhkan usaha yang lain untuk mencukupi kebutuhan keluarga. Setelah data dikelompokkan menurut (Tabel 6) jumlah tanggungan keluarga responden tergolong banyak, 3-4 orang adalah 54 responden (70,13\%), 5-6 orang adalah 18 responden $(23,38 \%), 1-2$ orang adalah 5 responden $(6,49 \%)$.

Hal ini sejalan menurut Siagian (2008) jumlah tanggungan keluarga yaitu jumlah seluruh orang yang ada didalam suatu rumah tangga yang harus diberikan nafkah oleh sang kepala keluaraga, semakin banyaknya jumlah tanggungan keluarga maka akan sejalan juga dengan meningkatnya kebutuhan rumah tangga.

Tabel 6. Jumlah Tanggungan Keluarga Responden

\begin{tabular}{cccc}
\hline No & $\begin{array}{c}\text { Jumlah Tanggungan Keluarga } \\
\text { (orang) }\end{array}$ & $\begin{array}{c}\text { Jumlah Responden } \\
\text { (orang) }\end{array}$ & $\begin{array}{c}\text { Persentase } \\
(\%)\end{array}$ \\
\hline 1 & $1-2$ orang & 5 & 6,4935 \\
2 & $3-4$ orang & 54 & 70,1299 \\
3 & $5-6$ orang & 18 & 23,3766 \\
4 & $>7$ orang & 0 & 0 \\
\hline Total & & $\mathbf{7 7}$ & $\mathbf{1 0 0}$ \\
\hline
\end{tabular}

Sumber : Data Primer (2014) 


\section{Pendapatan Keluarga}

Pendapatan Keluarga memiliki nilai koefisien regresi sebesar $-0,2335 \mathrm{di}$ mana nilai $\mathrm{P}$ sebesar 0,3627 yang lebih besar dari $\alpha 0,05$ yaitu tidak berpengaruh nyata. Dengan demikian artinya pendapatan peternak tidak mempengaruhi tingkat partisipasi peternak untuk mengikuti pelaksanaan program IB. Nilai min pada koefisen regresi $-0,2335$ hal ini menunjukan bahwa pengaruh berlawanan, apabila sekala usaha ternak potong sudah besar, pendapatan peternak akan tinggi dan keinginan untuk berpartisipasi dalam pelaksanaan program IB semakin menurun. Karena upaya untuk peningkatan usaha ternak potong dengan menggunakan program IB, tidak memberikan pengaruh terhadap peningkatan usaha. Berdasarkan hasil penelitian (Tabel 7) terlihat bahwa persentase pendapatan peternak dari usaha ternak potong bervariasi, pendapatan peternak terendah > $\mathrm{Rp} 1.000 .000$ dan tertinggi > $\mathrm{Rp} 2.000 .000$, setelah dikelompokan pendapatan responden $>\mathrm{Rp}$ 1.000.000 - 1.500.000 adalah 4 peternak $(5,19 \%),>\operatorname{Rp} 1.500 .000-2.000 .000$ adalah 53 peternak $(68,83 \%)$ dan $>\mathrm{Rp}$ 2.000.000 adalah 20 peternak $(25,97 \%)$.

Menurut Fuad (1997) besarnya skala usaha dapat menentukan tingkat pendapatan dan keuntungan para pelaku yang terlibat dalam mengusahakannya.

\section{KESIMPULAN}

Hasil analisa assesmen tingkat partisipasi perternak yang mempengaruhi secara nyata dalam pelaksanaan kegiatan inseminasi buatan adalah umur peternak dan jumlah ternak potong yang dimiliki responden. Berdasarkan hasil perhitungan koefisen determinasi $\left(\mathrm{r}^{2}\right)$ hanya memberikan sumbangan sebesar 0,1958 dari variabel independen terhadap variabel dependen.

Tabel 7. Pendapatan Keluarga Responden

\begin{tabular}{cccc}
\hline No & $\begin{array}{c}\text { Pendapatan Peternak } \\
(\text { Rp/bulan) }\end{array}$ & $\begin{array}{c}\text { Jumlah Responden } \\
\text { (orang) }\end{array}$ & $\begin{array}{c}\text { Persentase } \\
(\%)\end{array}$ \\
\hline 1 & $500.000-1.000 .000$ & 0 & 0 \\
2 & $>1.000 .000-1.500 .000$ & 4 & 5,1948 \\
3 & $>1.500 .000-2.000 .000$ & 53 & 68,8312 \\
4 & $>2.000 .000$ & 20 & 25,9740 \\
\hline Total & & $\mathbf{7 7}$ & $\mathbf{1 0 0}$ \\
\hline
\end{tabular}

Sumber : Data Primer (2014) 
Sedangkan berdasarkan hasil

perhitungan koefisen korelasi (r), variabel independen dari karakteristik responden terhadap variabel dependen tingkat partisipasi ini mempunyai hubungan yang lemah sampai dengan sedang, karena hanya sebesar 0,4425 masih jauh dari 1 .

\section{DAFTAR PUSTAKA}

Anonimus. 2014. Rekapitulasi Jumlah Sapi Potong dan Kerbau Hasil Sensus Pertanian. Dinas Pertanian Peternakan Kota Bengkulu.

Awang, San Arif. 1999. Forest for People Berbasis Ekosistem, et al. Pustaka Hutan Rakyat. Yogyakarta.

Fuad, Y. 1997. Usaha Peternakan Ayam Broiler. Kanisius. Jakarta.

Gujarati, D, 2003, Ekonometri Dasar. Terjemahan: Sumarno, Z. Erlangga. Jakarta

Mardikanto, T. 2009. Sistem Penyuluhan Pertanian. UNS Press, Surakarta.

Mittlboeck M, Schemper M. 1996. Explained Variation For Logistic Regresstion. Statistic in Medicine 15:1987.

Mosher, A.T, 1987. Menggerakkan dan Membangun Pertanian. Cetakan ke 12. Yasaguna, Jakarta.
Padmaningrum, D. 2014. Peran Penyuluh

Dalam Pengembangan Dan

Diseminasi Inovasi Peternakan

Kambing Peranakan Etawa Ras

Kaligesing Di Kabupaten

Purworejo (Prosiding) Semnas

Pembangunan Peternakan

Indonesia. UNS-Surakarta,

Oktober 2014 :238-240

Rogers, 1995. Diffusion Of Innovations Fourth Edition. The Free Press. New York.

Siagian, Sondang, 2008. Manajemen Sumber Daya Manusia (cetakan 15). Jakarta:

Bumi Aksara.

Soekartawi, A. 1996. Analisis Usahatani. Universitas Indonesia. Jakarta.

Soekartawi, A. 2005. Prinsip Dasar Komunikasi Pertanian. Universitas Indonesia. Jakarta.

Walker, E.L. 1973. Kondisi dan Proses Belajar Instrumental. Yayasan Penerbit UI, Jakarta.

Yumiati, Y., dan Yulihartika, R. 2014. Analisis Aspek sosial Ekonomi Program Inseminasi Buatan Ruminansia Potong di Kota Bengkulu. Proposal Penelitian Dosen Pemula. Lembaga Penelitian Universitas Dehasen 